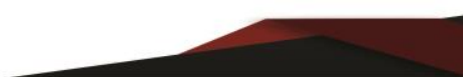

Artigo

\title{
A Educação do Aluno Surdo na Escola: Reflexões acerca do Ensino de Filosofia para Adolescentes Surdos
}

\author{
Alexsandra dos Santos Barbosa ${ }^{1}$; Jarles Lopes de Medeiros ${ }^{2}$
}

\begin{abstract}
Resumo: Este artigo objetivou refletir acerca do ensino de filosofia para adolescentes surdos. Uma das principais limitações que a pessoa surda encontra ainda é a limitação social, embora sejam inúmeras as barreiras que lhe dificulta o acesso ao conhecimento, ao lazer e à comunicação. Os resultados levam a crer que o preconceito iniciase no ambiente familiar, dificultando um diagnóstico precoce. Nesse panorama, parece cada vez mais difícil ao respeito a condição da pessoa surda, dificultando sua inclusão. Esperamos que esta discussão possa influenciar políticas públicas inclusivas mais eficazes.
\end{abstract}

Palavras-Chave: Educação. Aluno surdo. Ensino de filosofia.

\section{The Education of the Deaf Student at School: Reflections on the Teaching of Philosophy for Deaf Adolescents}

\begin{abstract}
This article aims to reflect on philosophy teaching for deaf adolescents. One of the main limitations that the deaf person encounters is still social limitation, although there are numerous barriers to access to knowledge, leisure and communication. The results lead one to believe that prejudice begins in the family environment, making it difficult to diagnose early. In this context, it seems increasingly difficult to respect the condition of the deaf person, making it difficult to include them. We hope that this discussion can influence more inclusive inclusive public policies.
\end{abstract}

Keywords: Education. Deaf student. Teaching of philosophy.

\section{Introdução}

Atualmente, as pessoas que sofrem com algum tipo de deficiência vêm conquistando espaço em forma de direitos na legislação brasileira. Existem leis que asseguram o direito de ir e vir a tais pessoas. Mas no dia a dia, no cotidiano desses indivíduos, a realidade é outra. Encontram dificuldades em todos os lugares, o seu direito de ir e vir, de possuir uma educação de qualidade, de exercer os seus direitos, de fato não existe na prática.

\footnotetext{
${ }^{1}$ Mestranda em Filosofia no Curso de Mestrado Profissional do Programa de Pós-graduação da Universidade Federal do Ceará (PROFILO/UFC). Graduada em Filosofia pela Universidade Federal do Ceará (UFC).Professora de Filosofia na Secretaria da Educação Básica (SEDUC). E-mail: alexsandrabarbosademoraes@gmail.com

${ }^{2}$ Doutorando em Educação no Programa de Pós-graduação em Educação Brasileira da Universidade Federal do Ceará (PPGE/UFC). Mestre em Educação (UFC). Especialista em Psicopedagogia Institucional e Clínica pela Faculdade da Aldeia de Carapicuíba (FALC). Graduado em Pedagogia pela Universidade Estadual do Ceará (UECE) e Licenciado em Língua Portuguesa pela Faculdade da Grande Fortaleza (FGF). Professor de Língua Portuguesa na SEDUC. E-mail: jarlles@hotmail.com
}

613 Id on Line Rev. Mult. Psic. V.12, N. 41, p. 613-626, 2018 - ISSN 1981-1179
Edição eletrônica em http://idonline.emnuvens.com.br/id 
Este artigo tem como objetivo suscitar reflexões acerca do ensino de filosofia para adolescentes surdos. E interesse nosso contribuir para as discussões na área da educação inclusiva, realizando o debate transdisciplinar, onde, de acordo com Dosse (2003), só se efetiva a partir da união de diferentes áreas do saber objetivando a criação de novos conhecimentos.

Para a realização deste estudo possui uma abordagem qualitativa. Deslandes (2011) destaca que o caráter qualitativo proporciona aos pesquisadores uma óptica subjetiva no trato com o objeto de estudo. Ao trabalhar com seres humanos, no caso os surdos, tal perspectiva se tornou fundamental ao nos debruçarmos sobre as particularidades de tais sujeitos levando em consideração o ensino de filosofia. Utilizamos, também, como recurso metodológico a abordagem teórico-bibliográfica, articulando as ideias de diferentes autores.

\section{Breve História da Educação Especial no Brasil}

Hoje temos em um mundo globalizado, capitalizado e, de certa forma, em desenvolvimento. Mediante esse contexto, parece responsabilidade do ser humano tratar o outro de forma igualitária, o que proporciona grande aprendizado. Se nos debruçarmos um pouco na história veremos como já fomos cruéis e desumanos com o diferente.

Ribeiro, Bezerra e Holanda (2015) destacam que graças à visão deturpada e ignorante de alguns, as pessoas com deficiência eram ligadas ao misticismo e ao ocultismo, logo marginalizadas, tratadas como lixo, descartadas da sociedade e escondidas dos olhos do povo. Há relatos que dizem que na Grécia, berço da filosofia e de muitas ciências, crianças recémnascidas eram sacrificadas ou escondidas e até mesmo abandonadas. Já na Roma, era permitido que os próprios pais eliminassem os seus filhos, afogando-os.

Nos séculos IV e V, continuam as autoras, vamos encontrar nos ensinamentos de Santo Agostinho, que atribuía à deficiência mental toda a culpa, punição e expiação de pecados dos antepassados. Seis séculos mais tarde, São Tomás de Aquino, tinha uma percepção mais amena quando entendia que as pessoas com deficiência sofriam de uma espécie de demência natural, não considerando seus males um pecado, propriamente dito.

A Idade Média foi marcada pela forte presença da igreja no Estado e, consequentemente, isso repercute por outros âmbitos da vida cotidiana, para as pessoas com deficiência talvez tenha 
sido o primeiro olhar que lhes foi lançado. Todos eram considerados filhos de Deus, inclusive as crianças. Sendo assim, elas não poderiam ser assassinadas como acontecia na Roma, por exemplo. Por outro lado, recebiam punições com a finalidade de se curar da deficiência e se livrar do mal que lhes foi lançado. Imediatamente, nosso pensamento de hoje é rejeitar essa visão contraditória, mas foi nesse momento histórico que começaram a surgir ações caritativas para proteger e cuidar desses sujeitos.

Alguns séculos a frente, a própria Igreja joga na fogueira as pessoas com deficiência mental, os endemoniados e as bruxas. Por um longo período de tempo, as deficiências mentais foram associadas a causas malignas. Somente com o Renascimento, o fortalecimento das ciências e a valorização da racionalidade que começaram a surgir alguma mudança. A verdade sobre a causa da deficiência passa a ser buscada na ciência e não na Igreja, com os conhecidos e renomados Paracelso e Cardano (RIBEIRO, BEZERRA e HOLANDA, 2015).

Seguindo a linha histórica, é possível perceber que a história da educação da pessoa com deficiência tem pequenos e longos saltos, dependendo do seu período e de modo geral do entendimento das pessoas. Vimos que na Grécia e na Roma havia o assassinato, já no período de regência da Igreja tínhamos uma política de caridade. Na modernidade prevalecia o tratamento médico em detrimento ao educacional.

Assim, na Idade Antiga os deficientes eram mortos, pois acreditava-se que eles não eram úteis para a sociedade, uma vez que não serviam para combater os inimigos na guerra. Na Idade Média, onde política e religião se confundiam numa relação intrínseca, as pessoas com deficiência eram segregadas em instituições, isoladas da sociedade. Tais instituições tinham apenas um caráter assistencialista, de cuidados, não havia um plano educacional destinado para tais pessoas.

Na Idade Moderna, a segregação continuou, embora tenha iniciado o atendimento educacional para os “deficientes". A partir do século XX, o movimento da educação integrada , o paradigma da inclusão ganha cada vez mais força, o que reflete na legislação e no social.

No contexto brasileiro, as primeiras iniciativas para a organização de serviços de atendimento especial começaram no século XIX, inspirados em experiências ocorridas na Europa e nos Estados Unidos. Nesse primeiro momento, foram atendidos surdos, cegos, deficientes mentais e deficientes físicos.

Em dezembro de 1883 ocorreu o Primeiro Congresso de Instrução Pública, convocado pelo Imperador. Um dos temas que foi sugerido foi Currículo e formação de professores para 
cegos e surdos. Ainda no período imperial, existiram ações voltadas para o atendimento médico-pedagógico em Salvador. Na primeira metade do século XX havia mais de quarenta estabelecimentos de ensino regular especial mantidos pelo próprio governo, além dos muitos estabelecimentos particulares.

\begin{abstract}
[...] o primeiro atendimento escolar especial teve seu início através de um decreto do Imperador Dom Pedro II em 1854 no Rio de Janeiro. Foi criado o Imperial Instituto dos Meninos Cegos graças à influência de um médico da família imperial. Em 1891 a escola passou a se chamar Instituto Benjamin Constant. Ainda no governo de Dom Pedro II foi fundado o Imperial Instituto dos Surdos-Mudos, que desde o seu início se caracterizou como um estabelecimento educacional voltado para a educação literária e o ensino profissionalizantes de meninos entre 7 e 10 anos de idade. Em ambos os institutos, foram criadas oficinas, como, por exemplo, de encadernação e de tricô (MOZZOTTA, 1996, p.29).
\end{abstract}

Mozzota (1996) segue a análise destacando que a partir da segunda metade do século XX o Governo Federal assume campanhas nacionais específicas para o atendimento de pessoas com necessidades especiais, a primeira foi pela educação de surdos. Em 1958 é criada a Campanha Nacional de Educação e Reabilitação de Deficientes da Visão vinculada ao Instituto Benjamin Constant. Já na década de 1960 surge uma nova Campanha, a de Educação e Reabilitação de Deficientes Mentais, CAMEDE, que seria conduzida pelo ministro da educação.

Em 1971 é aprovada uma lei que prevê "tratamento especial aos excepcionais" e coloca a questão no ensino regular. No ano seguinte, é criado um Grupo- Tarefa de Educação Especial. Dentre as tarefas do grupo, a vinda do especialista em educação especial norte- americano James Gallagher. O especialista apresentou um relatório de planejamento para o Grupo-Tarefa contendo propostas para a estruturação da educação especial. O relatório contribuiu para a criação de um órgão central responsável pelo atendimento dos excepcionais no Brasil, o Centro Nacional de Educação Especial- CENESP (MAZZOTTA, 1996).

Com a criação do CENESP, foram extintas as campanhas e a verba das mesmas foram revertidas para o centro. Depois de quinze anos e de algumas gestões, o Centro de Educação foi transformado em Secretaria de Educação Especial- SESPE. Foram mantidas basicamente as mesmas atribuições do Centro, porém a sede passou do Rio de Janeiro para Brasília e como Secretário de Educação Especial foi nomeado um ex. Deputado, advogado, que nunca tinha atuado com Educação Especial. Em 1990, a SESPE foi extinta, suas atribuições passaram a ser 
da Secretaria Nacional de Educação Básica- SENEB. Em 1992, com a queda do Governo Collor de Melo, houve mais uma reorganização e reapareceu a Secretaria de Educação Especial.

Já em 1999, destaca Januzzi (2004), no Governo Fernando Henrique Cardoso, foi criado o CONADE, Conselho Nacional dos Direitos da Pessoa com deficiência, que deve acompanhar o desempenho dos programas e projetos da administração pública responsável pela Política Nacional para Integração da pessoa portadora de deficiência. O CONADE é paritariamente constituído por pessoas da sociedade civil e governo, embora o ministro da justiça disponha sobre os critérios de escolha dos representantes. O Conselho existe até os dias atuais.

Em 2001, um decreto coloca a meta de 10 anos para atingir o equivalente a $5 \%$ dos recursos vinculados à manutenção e ao desenvolvimento do ensino. Em 2002 LIBRAS- Língua Brasileira de Sinais, é reconhecida como meio legal de comunicação e expressão, bem como a inclusão da disciplina de Libras no currículo dos cursos de formação de professores.

Em 2003, é implementado pelo MEC o Programa "Educação Inclusiva: direito à diversidade", com vistas a apoiar a transformação dos sistemas de ensino em sistemas educacionais inclusivos, promovendo um amplo processo de formação de gestores e de educadores nos municípios brasileiros para a garantia do direito a todos à escolarização, à oferta do atendimento educacional especializado e à garantia de acessibilidade (MATOS, 2011).

Dessa forma, através da compreensão histórica acerca da educação especial no Brasil é possível compreender as dificuldades que circundam a efetivação do processo de educação inclusiva dos sujeitos, sobretudo dos surdos. Apesar dos avanços, os alunos com essa condição são vistos como incapazes, tendo suas potencialidades negligenciadas e subestimadas.

\section{Educação Inclusiva e os Desafios para o Surdo no Brasil}

Para compreensão da atual situação das pessoas surdas no sistema educacional brasileiro é necessário suscitar reflexões acerca da história da educação inclusiva no mundo com um enfoque particular na história da educação inclusiva no Brasil. Ao longo da história da humanidade, seres humanos nascem com necessidades especiais. Para muitas deficiências, ainda se buscam a causa, uma suposta cura, como também formas de conviver com as possíveis 
limitações que os sujeitos apresentem. Sabe-se que algumas têm sua origem em causas externas e/ou ambientais, outras são genéticas, dentre outros fatores.

Independente da causa, hoje sabemos que pessoas deficientes têm muitas potencialidades, assim como as ditas normais, e que um dos caminhos para o desenvolvimento de todo e qualquer tipo de potencialidade é a educação. Em alguns contextos históricos é possível perceber como pessoas deficientes sofreram, e ainda sofrem, preconceitos ou foram excluídas da vida em sociedade, sendo até mesmo mortas em virtude de suas deficiências. Tal exclusão também se reflete no processo educacional oferecido pela escola, fazendo com que não se efetive o direito a educação assegurando pela Constituição Federal (BRASIL, 1988).

Poderemos perceber, também, que alguns núcleos da sociedade se reuniram para receber, ou mesmo amparar, essas pessoas, alguns de forma precária e em contraponto a práticas de extermínio e de discursos patológicos e agressivos. Alguns desses esforços de inclusão são materializados em legislações, mesmo que de forma primária, como podemos observar na Constituição Federal (BRASIL, 1988), O Estatuto da Criança e do Adolescente - ECA (BRASIL, 1990) e a Lei de Diretrizes e Bases da Educação Nacional Brasileira - LDB (BRASIL, 1996).

O conceito de inclusão é algo relativamente novo e nos remonta a meados do século $\mathrm{XX}$, momento em que políticas sociais e educacionais começaram a ser criadas para pessoas deficientes. Mesmo assim, os seus direitos são negados, muitas vezes por falta de informação e/ou entendimento, tendo como base ópticas preconceituosas. Nesse sentido, Freire (2008), destaca que:

\begin{abstract}
A inclusão é um movimento educacional, mas também social e político que vem defender o direito de todos os indivíduos participarem, de uma forma consciente e responsável, na sociedade de que fazem parte, e de serem aceites e respeitados naquilo que os diferencia dos outros. No contexto educacional, vem, também, defender o direito de todos os alunos desenvolverem e concretizarem as suas potencialidades, bem como de apropriarem as competências que lhes permitam exercer o seu direito de cidadania, através de uma educação de qualidade, que foi talhada tendo em conta as suas necessidades, interesses e características (p.5).
\end{abstract}

Dentro de uma perspectiva positiva, é possível apontar um grande avanço quando se diz respeito à garantia do direito da pessoa deficiente e a políticas educacionais voltadas para a inclusão social e escolar. Algo que reforça esse dado é o número crescente de profissionais que 
se voltam para área da educação inclusiva e o fortalecimento de comunidades e grupos sociais, como a Comunidade Surda, por exemplo.

De acordo com o Ministério da Educação - MEC os dados do Censo Escolar indicam um crescimento expressivo em relação às matrículas de alunos com deficiência na escola regular $^{3}$. Em 1998, cerca de 200 mil pessoas estavam matriculadas na educação básica, sendo apenas 13\% em classes comuns. Em 2014, eram quase 900 mil matriculadas e $79 \%$ delas em turmas comuns. Houve um crescimento de $400 \%$ nos últimos 15 anos.

Sobre a matrícula de alunos surdos, Quiles (2015) informa que estes representam apenas $10 \%$ do número de alunos matriculados com Necessidades Educacionais Especiais - NEE. A autora aponta para o aumento do número de matrícula de surdos, porém ainda é um percentual tímido. Os surdos não são considerados deficientes.

Assim, a legislação brasileira avança rumo ao progresso da inclusão, teoricamente. Mas a moral e os costumes permanecem estáticos, muitas vezes com o mesmo pensamento do século passado, onde o deficiente não tem vez, onde inclusão significa simplesmente aceitar, tolerar, sem dar maiores importâncias. Nesse sentido, a inclusão não passa de um "favor" que oferecemos aos surdos. O pré-conceito contra as pessoas com deficiência é uma herança histórica que perdura até os dias de hoje. Houve muitos avanços, mas muita coisa ainda precisa ser melhorada.

\section{Cultura Surda}

Para refletirmos as fundamentações da educação de surdos atual, não há nada melhor do que fazer um breve percurso pelas raízes da história de surdos. A história da educação de surdos não é uma história difícil de ser analisada e compreendida, ela evolui continuamente apesar de vários impactos marcantes. No entanto, vivemos momentos históricos caracterizados por mudanças, turbulências e crises, mas também de surgimento de oportunidades. O interessante é que estas decisões sobre a educação de surdos sempre foram determinadas por sujeitos ouvintes que se autoconferem o poder para a tomada dessa decisão.

\footnotetext{
${ }^{3}$ Disponível em: < http://portal.mec.gov.br/ultimas-noticias/202-264937351/21439-numero-de-matriculas-depessoas-com-deficiencia-cresce-no-brasil>. Acesso em: Abril/2018.
} 
Antes de surgirem discussões sobre a educação, os sujeitos surdos eram rejeitados pela sociedade e posteriormente eram isolados nos asilos para que pudessem ser protegidos, pois não se acreditava que pudessem ter uma educação em função da sua "anormalidade". Essa conduta, marcada pela intolerância obscura, na visão negativa sobre os surdos, concebiam-nos como anormais ou doentes.

Com o passar do tempo, os sujeitos surdos passam a ser vistos como cidadãos com direitos e deveres de participação na sociedade, mas sob uma visão assistencialista excluída. Naquela época, não tinham escolas para os sujeitos surdos. Com a preocupação educacional dos surdos, fizeram surgir cursos de formação para professores que desenvolveram seus trabalhos com os sujeitos surdos e de diferentes métodos de ensino.

Para a população surda foi difícil viver durante a Antiguidade devidas às injustiças sofridas e suportadas, como já mostrado anteriormente. Uma breve visão através da história de educação de surdos nos possibilita uma reflexão de como o sujeito surdo foi tratado e educado através dos tempos e nos permite compreender atitudes atuais dos profissionais da saúde e da educação, causadores de estereótipos que permeiam as diferentes representações na educação de surdos.

A maioria dos pesquisadores discretamente se limitaram nos registros nos quais os sujeitos surdos eram vistos como seres deficientes, conforme a definição de "ouvintismo", assim como pronuncia a pesquisadora surda Perlin (2006): "As narrativas surdas constantes à luz do dia estão cheias de exclusão, de opressão, de estereótipos" (p.80).

Nós não podemos deixar de reconhecer que a história do povo surdo mostra que por muitos séculos de existência, a Pedagogia, as políticas e muitos outros aspectos próprios do povo surdo têm sido organizados geralmente no ponto de vista dos sujeitos ouvintes e não dos sujeitos surdos que, quase sempre, são negligenciados como profissionais que poderiam contribuir com suas competências essenciais e de sua diferença do ser surdo.

O Ser Surdo é olhar a identidade surda dentro dos componentes que constituem as identidades essenciais com as quais se agenciam as dinâmicas de poder. É uma experiência na convivência do ser na diferença". (PERLIN E MIRANDA, 2003, p.217).

Os surdos, a partir da Língua Brasileira de Sinais (LIBRAS), formam um conjunto de meios comunicativos que garantem uma interação sociocultural. Dessa forma, como todos, por 
sermos diferentes, possuem uma cultura e nela se constroem arranjos que vão se adaptando de acordo com a realidade.

A palavra "cultura" abrange várias formas artísticas, mas define tudo aquilo que é produzido a partir da inteligência humana. Ela está presente desde os povos primitivos em seus costumes, sistemas, leis, religião, em suas artes, ciências, crenças, mitos, valores morais e em tudo aquilo que compromete o sentir, o pensar e o agir das pessoas. Assim, a LIBRAS constitui uma parte da Cultura Surda, já que é uma produção concebida a partir da inteligência humana. Essa pode ser encontrada com suas diferentes variações e descrita nas mais diversas nacionalidades.

De uma forma geral, a cultura surda nos passa a impressão e compreensão de que nela não existem barreiras em compartilharem de um viver multicultural em sociedade. As maiores barreiras partem muito mais da falta de conhecimento que as pessoas ainda possuem em relação a ela própria.

O reconhecimento da importância da LIBRAS, bem como da possibilidade de dar a todos a garantia de expressão de seus sentimentos e ideais é reconhecer que surdez não é uma deficiência, mas sim uma cultura, e é dessa forma que a comunidade surda gosta de ser identificada. O respeito a essas pessoas é fundamental para uma convivência adequada. Os surdos não são inferiores aos ouvintes, são seres com capacidade intelectual e cognitiva como qualquer outro. Sua limitação não atrapalhará o seu desenvolvimento se todos nós agirmos de uma maneira natural, compreendendo as dificuldades e possibilitando o desenvolvimento de suas potencialidades.

\section{Ensino de Filosofia e a Comunidade Surda}

A filosofia passou a ser disciplina obrigatória no currículo do Ensino Médio em 2009 com a Lei $\mathrm{n}^{\mathrm{o}} 11.689$, de 2008, depois de ter sido retirada no período da ditadura militar em prol de dar espaço a disciplinas como Moral e Cívica e Organização Social e Política do Brasil. Depois de seu retorno, muito se tem pensando sobre a metodologia de ensino que deve ser adotada para as turmas regulares. Algumas discussões entre filósofos e educadores debatem a 
questão, porém, são poucos os trabalhos sobre o ensino de filosofia para surdos, concebendo a disciplina como obrigatória no Ensino Médio.

No entanto, a partir do ano de 2017, o que se observa é uma desvalorização desse ensino, a exemplo da não obrigatoriedade da Filosofia no currículo do Ensino Médio (Lei no 13.415, de 2017). Situação parecida ocorreu na década de 1960, no período histórico compreendido como Ditadura Militar, quando houve o intuito de reforçar uma educação tecnicista, focada no mercado de trabalho que preza pela mão de obra barata de um trabalhador passivo diante da complexidade social.

O ensino de filosofia, como dito, passou a ser disciplina obrigatória no currículo do Ensino Médio há poucos anos, sendo retirada a sua obrigatoriedade há pouco mais de um ano. Mesmo com isso, muito se tem pensado sobre como deve ser esse ensino, que metodologia deve ser adotada e que tipo de formação o professor da área deve possuir. Nesse sentido, Gallo (2007) compreende que ensinar filosofia é ensinar a criar conceitos filosóficos. O teórico em questão se embasa no pensamento de Deleuze e Guatarri (2012) para justificar sua teoria sobre o ensino de filosofia no Ensino Médio.

Mesmo com muitos autores brasileiros se debruçando sobre a questão do ensino de filosofia nessa modalidade de ensino, pouco se tem pesquisado sobre o ensino de filosofia para adolescentes surdos. Durante uma rápida busca no site da Biblioteca Digital Brasileira de Teses e Dissertações ${ }^{4}$ em busca de trabalhos realizados sobre a temática "Ensino de Filosofia e Surdez" não foi encontrado nenhuma referência.

Em algumas pesquisas, encontramos trabalhos sobre ensino de matemática para surdos (OLIVEIRA, 2014), ensino de química (MACHADO, 2016) e até mesmo softwares de computadores (LOPES, 2006) criados para contribuir para a escolarização do grupo em questão. Porém, não foram encontradas pesquisas sobre o ensino de filosofia para surdos. A grande preocupação é a falta de existência de sinais para conceitos filosóficos. Sem sinais, o surdo não pode criar tais conceitos sem se recorrer ao alfabeto manual, a datilologia. É fundamental que os adolescentes surdos e ouvintes possam criar conceitos filosófico e, assim, apropriarem-se dos conceitos filosóficos.

A Comunidade Surda, como muita persistência, mas também resistência, vem ganhando espaço e paulatinamente conquistando direitos. A oficialização da Língua Brasileira de Sinais

\footnotetext{
${ }^{4}$ Este site reúne as dissertações e teses de mais de 490 mil pesquisas realizadas em universidades brasileiras. Disponível em: < http://bdtd.ibict.br/vufind/>. Acesso em: Abril/2018.
} 
- LIBRAS, pela Lei 10.436 de 24 de abril de 2002 (BRASIL 2002) e o Decreto Federal 5.626 de 22 de dezembro de 2005 (BRASIL, 2005) são exemplos dessas conquistas, porém a muito a se fazer.

Hoje o método adotado por algumas instituições de ensino para a escolarização do surdo é o bilinguismo. Este recurso metodológico consiste em trabalhar com duas línguas no contexto escolar, a saber, Libras, como língua oficial do aluno surdo, e o Português como língua escrita secundária. É importante mencionar que a criança ou adolescente deve ter contato com a Libras desde a Educação Infantil, tendo português apenas como segunda língua.

Existem pesquisas sobre o bilinguismo surdo e sobre a escolarização do surdo no Brasil. Queiroz (2013) esclarece que para a efetivação do bilinguismo é fundamental as mudanças e diferentes concepções que circundam o sujeito surdo. Isso envolve, também, as políticas educacionais, tais como as regulamentações citadas anteriormente. Torna-se essencial um processo educativo que tenha como escopo a inclusão e metodologias que propiciem práticas pedagógicas que valorizem a Cultura Surda.

Diante do exposto, o professor de filosofia encontra inúmeros desafios em suas aulas ao ministrar os conteúdos. Existem muitos conceitos filosóficos que não possuem sinais na LIBRAS, o que dificulta a tradução que o intérprete oferece ao aluno. Existe aí também uma questão epistemológica, onde o intérprete não possui formação que lhe assegure uma explicação do conteúdo abordado em sala de aula. O resultado disso é que o aluno surdo criar lacunas teóricas, acabado ficando alheio a certos conceitos filosóficos.

\section{Considerações Finais}

Os surdos são excluídos diariamente em nossa sociedade. Num primeiro instante, as pessoas se interessam em aprender algumas palavras em LIBRAS, mas logo perdem o interesse, pois julgam ser muito difícil aprender. Desrespeitam os surdos ao falar do lado deles o que querem, com a justificativa que eles não irão compreender. Precisamos mudar esse pensamento, essa cultura.

O termo inclusão vem sendo discutido há muito tempo, e pouco tem se efetivado nas vidas das pessoas surdas. Inclusão vem se confundindo ao longo do tempo com tolerância. 
Inclui-se, mas não há respeito, não há sensibilidade, não se dedica importância para os sujeitos que sofrem com algum tipo de deficiência, seja ela física, mental, visual, etc. Tais pessoas se tornam invisíveis em nossa sociedade.

Permitimos a sua entrada, mas dificultamos o seu trânsito. Não trabalhamos em equipe com elas, pois julgamos que são inferiores, que não podem: o fato é assustador, mas, de uma forma geral, subestimamos a pessoa com deficiência, não lhe oferecemos oportunidades. Aliás, o termo "deficiência” já é pejorativo por si só, e reflete o nosso preconceito.

A principal limitação que a pessoa surda encontra ainda é a limitação social. Existem inúmeras barreiras que lhe dificulta o acesso ao conhecimento, bem como o acesso ao lazer e à comunicação. E, muitas vezes, o preconceito e as barreiras se iniciam em casa, com a própria família, que em alguns casos possuem dificuldades em aceitar ou diagnosticar a surdez.

Nesse panorama, onde o egoísmo toma o espaço, cada vez mais restrito, da empatia e da compaixão, trava-se uma guerra silenciosa, velada, onde só há um vencedor: o pré-conceito. E isso é o que mais dificulta a inclusão das pessoas surda. Existe uma barreira social bastante cultuada em nossa sociedade, à qual impede algumas pessoas de exercer o seu pleno desenvolvimento, o seu papel de cidadão de direitos.

\section{Referências}

BRASIL. Constituição da República Federativa do Brasil. 1988

Lei $\mathbf{n}^{0}$ 9.393, de 20 de dezembro de 1996. Estabelece as Diretrizes e Bases da Educação Nacional. Brasília, 1996.

. Lei no 8.069 de 13 de julho de 1990. Estatuto da Criança e do Adolescente. Brasília, 1990.

Decreto $\mathrm{n}^{\mathbf{0}} \mathbf{5 . 6 2 6}$ de 22 de dezembro de 2005. Disponível em: < http://www.planalto.gov.br/ccivil_03/_ato2004-2006/2005/decreto/d5626.htm>. Acesso em: Abril/2018.

Lei 10.436 de 24 de abril de 2002. Disponível em: < http://www.planalto.gov.br/ccivil_03/leis/2002/110436.htm>. Acesso em: Abril/2018.

DELEUZE, Gilles e GUATTARI, Félix. O que é filosofia. Rio de Janeiro: 34, 2012. 
DESLANDES, Suely Ferreira; GOMES, Romeu; MINAYO, Maria Cecília de Souza (org). Pesquisa social: teoria, método e criatividade. $30^{\circ}$ ed. Petrópolis, RJ:Vozes, 2011.

DOSSE, François. Uma transdisciplinaridade. In: O império do sentido: a humanização das Ciências Humanas. Tradução Ilka Stern Cohen. Bauru, SP: EDUSC, 2003.

FERNANDES, Luana Paula Tiné Costa. Crianças e jovens: vítimas e/ou agentes de violência. Monografia (Graduação). 45f. Rio de Janeiro, 2012.

FREIRE, Sofia. Um olhar sobre a inclusão. Revista da Educação. V. XVI, nº 1, p. 5-20, 2008.

GALLO, Sílvio. Deleuze e a Educação. Belo Horizonte. Autêntica, 2003.

JANUZZI, G. M. A educação do deficiente no Brasil: dos primórdios ao início do século XXI. Campinas: Autores Associados, 2004.

LOPES, Ligiane de Castro. A produção textual de alunos surdos sob a mediação de softwares educativos. Dissertação (Mestrado). 153f. Universidade Federal do Ceará. Programa de Pós-graduação em Educação. Fortaleza, 2006.

MACHADO, Raquel Brusco. Ensino de Química: a inclusão de discentes surdos. Dissertação (Mestrado). 84f. Instituto Federal do Rio Grande do Sul. Instituto de Ciências Básicas da Saúde. Programa de Pós-graduação em Ciências Biológicas. Porto Alegre, 2016.

MATOS, Neide da Silveira Duarte de. A Educação Especial e a Formação de Professores proposta pelo Programa "Educação Inclusiva: Direito à Diversidade". Universidade Estadual do Oeste do Parana, 2011.

MOZZOTTA, Marcos José Silveira. Educação Especial no Brasil: História e políticas públicas. São Paulo: Cortez, 1996.

QUILES, Raquel Elizabeth Saes. Educação de surdos e deficientes auditivos: uma análise dos indicadores sociais. Revista Educação Especial, v. 28, nº 51, p. 53-66, 2015.

OLIVEIRA, Miguel Luiz Veiga de. Ensino de Matemática para surdos e ou cegos. Dissertação (Mestrado). 62f. Universidade Federal de Juiz de Fora. Instituto de Ciências Exatas. Juiz de Fora, 2014.

PERLIN, G. T. Surdos: cultura e pedagogia. In. THOMA, A. S., LOPES, M. C. (org). A invenção da surdez II: espaços e tempos de aprendizagem na educação de surdos. Santa Cruz do Sul, EDUNISC, 2006.

PERLIN Gladis e MIRANDA WILSON. Surdos: o Narrar e a Política. In: Estudos Surdos Ponto de Vista: Revista de Educação e Processos Inclusivos $n^{\circ} 5$, UFSC/ NUP/CED, Florianópolis, 2003. 
QUEIROZ, Esmeralda Ferreira. Contribuições da Sociolinguística Educacional à formação do professor alfabetizador/letrador de alunos surdos. Tese (Doutorado). 243f. Universidade de Brasília. Faculdade de Educação. Departamento de Métodos e Técnicas. Programa de Pósgraduação em Educação. Brasília, 2013.

RIBEIRO, Renata Rosa Russo Pinheiro Costa; BEZERRA, Tarcileide Maria Costa; HOLANDA, Telma Regina Pessoa. História e política da educação especial: da exclusão à inclusão. In: SANTOS, Geandra Claúdia Silva; RIBEIRO, Renata Rosa Russo Pinheiro Costa; SAMPAIO, Rosa Maria Goes; PINTO, Soraya Eli Lyra (org). Inclusão: saberes, reflexões e possibilidades de uma prática em construção. Fortaleza: EdUECE, 2015.

\section{Como citar este artigo (Formato ABNT):}

BARBOSA, Alexsandra dos Santos; MEDEIROS, Jarles Lopes de. A Educação do Aluno Surdo na Escola: Reflexões acerca do Ensino de Filosofia para Adolescentes Surdos. Id on Line Rev.Mult. Psic., 2018, vol.12, n.41, p.613-626. ISSN: 1981-1179.

Recebido: $23 / 04 / 2018$

Aceito 11/07/2018 